\title{
Antioxidant Status and Lipid Peroxidation in Diabetic Rats under Hyperbaric Oxygen Exposure
}

\author{
T. MATSUNAMI ${ }^{1}$, Y. SATO ${ }^{1}$, T. SATO ${ }^{1}$, M. YUKAWA ${ }^{1}$ \\ ${ }^{1}$ Laboratory of Biomedical Science, Department of Veterinary Medicine, College of Bioresource \\ Sciences, Nihon University, Fujisawa, Japan
}

Received November 5, 2008

Accepted January 28, 2009

On-line February 27, 2009

\begin{abstract}
Summary
Hyperglycemia is known to cause oxidative stress that leads mainly to enhanced production of mitochondrial reactive oxygen species (ROS). It has been demonstrated that hyperbaric oxygen (HBO) treatment also increases the formation of ROS. There are, however, no comprehensive evaluations of such oxidative effects in diabetes which requires HBO treatment. The purpose of this study is to investigate the influence of a clinically-recommended HBO treatment on glucose homeostasis and oxidative stress in rats with streptozotocin (STZ)-induced diabetes. Under the clinically-used HBO exposure protocol, the levels of blood glucose, thiobarbituric acid reactive substances (TBARS) as a lipid peroxidation marker, and the activity of superoxide dismutase (SOD) as an antioxidant enzyme marker were investigated in the erythrocytes, liver, pancreas, skeletal muscle, and brain of rats with STZ-induced diabetes. The levels of blood glucose and TBARS increased significantly $(p<0.05)$, and the activity of SOD decreased significantly $(p<0.05)$ in the erythrocytes and all organs of rats with diabetes subjected to $\mathrm{HBO}$ exposure. These results suggested that $\mathrm{HBO}$ exposure might boost glucose autoxidation and increase ROS production in STZ-induced diabetes as side-effects of administering HBO treatment for the first time.
\end{abstract}

\section{Key words}

Hyperbaric oxygen • Oxidative stress • Diabetic rats • Lipid peroxidation • Antioxidant enzyme

\section{Corresponding author}

Yukita Sato, Laboratory of Biomedical Science, Department of Veterinary Medicine, College of Bioresource Sciences, Nihon University, Fujisawa 252-8510, Japan. Fax: +81-466-84-3445. E-mail: sato.yukita@nihon-u.ac.jp

\section{Introduction}

Reactive oxygen species (ROS) which cause cellular damage by the oxidation ability have been implicated in the pathogenesis of diabetes mellitus (Brownlee 2001, Kowluru et al. 2007). During diabetes, persistent hyperglycemia increases the production of ROS through glucose autoxidation (Hunt et al. 1990, Wolff et al. 1991). The oxidative stress has also been associated with diabetic states in animals and humans (Kakkar et al. 1995, Ihara et al. 1999, Opara 2002, Davì et al. 2005). One of these studies using streptozotocin (STZ)-induced diabetic rats showed that levels of lipid peroxidation had increased, as indicated by thiobarbituric acid reactive substances (TBARS), which is one of oxidative stress markers suggesting the occurrence of oxidative stress (Kakkar et al. 1995). Moreover, diabetic patients have significant defects in antioxidant defense elements, and enhanced ROS generation is one of the major determinants of diabetic complications (Ihara et al. 1999, Opara 2002). Thus, diabetes closely relates to various oxidative activities.

Hyperbaric oxygen (HBO) therapy is achieved by exposing patients to breathing $100 \% \mathrm{O}_{2}$ at barometric pressure higher than ambient (1 atmosphere absolute or 1 ATA). HBO therapy is a unique method used in the treatment of various illnesses and clinical conditions, such as carbon monoxide poisoning, decompression sickness, osteomyelitis, and even diabetic foot (Feldmeier 2003). The Undersea and Hyperbaric Medical Society (UHMS) has an approved list of clinical conditions where HBO treatment is indicated including the above-mentioned disorders 
(Feldmeier 2003). However, it has been demonstrated that $\mathrm{HBO}$ also increases the formation of ROS that can cause cellular damage through the oxidation of lipids, proteins and DNA (Speit et al. 2002). It is also assumed that hyperoxic injury occurs via the metabolic production of oxygen radicals and related ROS, owing to the saturation of natural antioxidant defense mechanisms in the cells (Sies 1997).

HBO administration can also lead to unwelcome side-effects, such as oxidative stress and/or oxygen toxicity. Such side-effects have often been associated with the exposure to HBO levels much higher than those generally used for treating clinical conditions (Harbin et al. 1990, Torbati et al. 1992, Chavko et al. 1996, Speit et al. 2002). The clinically approved maximum pressure and duration of HBO exposure are 3 ATA and $120 \mathrm{~min}$, respectively (Feldmeier 2003), although the most commonly-used protocol for standard therapeutic purposes is slightly lower (1.8-2.8 ATA for 60-90 min) (Benedetti et al. 2004). The oxidative effects of HBO have been investigated in animals and humans (Eken et al. 2005, Oter et al. 2005, Korkmaz et al. 2008). One study on the effects of $\mathrm{HBO}$ in rats revealed that, after $2 \mathrm{~h}$ of HBO exposure at $3 \mathrm{ATA}$, elevated levels of the oxidative stress markers, TBARS and superoxide dismutase (SOD), were found in the lung, brain and erythrocytes (Oter et al. 2005). Thus, HBO exposure seems to be an excellent model system for investigating oxidative stress.

HBO treatment is used for the treatment of diabetic patients with unhealing foot ulcers (Feldmeier 2003). However, the side-effects of HBO treatment in diabetic patients have been poorly investigated. Previously, we have reported that a clinicallyrecommended HBO treatment caused a significant increase of glucose toxicity and decrease of insulin immunoreactive $\beta$-cells in STZ-induced diabetic rats (Matsunami et al. 2008). There are, however, no comprehensive articles describing the evaluation of such oxidative effects in diabetes with $\mathrm{HBO}$ treatment.

To evaluate the oxidative stress of $\mathrm{HBO}$ in STZ-induced diabetes, we examined levels of TBARS, the activity of antioxidant enzymes, and the physiological parameters associated with glucose homeostasis under HBO treatment, using pressure levels and duration of exposure to HBO typical of those used in the clinical setting.

\section{Materials and methods}

\section{Animals}

Twenty-four adult (12-week-old) male SpragueDawley rats (body weight 300-350 g), bred in our laboratory, were used for the experiment. They were housed at $23-25^{\circ} \mathrm{C}$ with light from 7:00 AM to 7:00 PM and free access to water at all times. All rats were fed a commercial diet during the experiment. All study procedures were implemented in accordance with the Institutional Guidelines for Animal Experiments at the College of Bioresource Sciences, Nihon University under the permission of the Committee of Experimental Animal in our college.

\section{Study design}

The rats $(n=24)$ were allowed to acclimatize for one week, prior to treatment and randomly distributed into four groups (6 rats per group): non-diabetic induction in the non-HBO group (Control), non-diabetic induction in the HBO group (HBO), diabetic induction in the non$\mathrm{HBO}$ group (DM), and diabetic induction in the HBO group (DM + HBO), respectively. The animals were kept for 9 days from the first treatment for diabetic induction. In this study, diabetes occurred on the third day after diabetic induction, and then HBO exposure has been conducted once daily for 7 days in DM + HBO group. The mean body weight of the animals in all groups was measured at the onset and end of the study period.

\section{Induction of diabetes}

Sprague-Dawley rats were injected intraperitoneally (i.p.) with $80 \mathrm{mg} / \mathrm{kg}$ of streptozotocin (STZ, Wako Pure Chemical Industries, Ltd. Japan), dissolved in citrate buffer ( $\mathrm{pH}$ 4.5), to induce diabetes as described previously (Like et al. 1976). Control and HBO rats were treated with equal volume and concentration of STZ injection vehicle, citrate buffer. Blood glucose levels in the auricular veins were measured 3, 6 and 9 days after STZ injection by an automated glucose measurement instrument, the G meter ${ }^{\circledR}$ (Sanofi-Aventis K.K. Japan). Diabetes was considered to have been induced when the blood glucose level reached at least $15.6 \mathrm{mmol} / 1$ (Matkovics et al. 1997).

\section{HBO exposure}

For all experiments referring to the clinicallyused setting, HBO was applied at a pressure of 2.8 ATA for $2 \mathrm{~h}$, once daily for 7 days, in a hyperbaric chamber for 
small animals (Nakamura Tekko-sho K.K., Tokyo, Japan). The ventilation rate was 4-5 1/min. Each exposure was started at the same hour in the morning (10 AM) to exclude any confounding issues associated with the changes in biological rhythm.

\section{Tissue preparation}

After the final exposure to $\mathrm{HBO}$, the rats were weighed and anesthetized with sodium pentobarbital (40 mg/kg i.p.). A 2-ml blood sample was collected by cardiac puncture and divided into three heparinized tubes, and various organs (brain, liver, pancreas, and skeletal muscle) were removed and washed with phosphatebuffered saline (PBS), $\mathrm{pH} 7.4$, containing $0.16 \mathrm{mg} / \mathrm{ml}$ of heparin to remove any red blood cells (erythrocytes) and clots (Prasad et al. 1992). Brain, liver, pancreas, and skeletal muscle were homogenized with an ultrasonic homogenizer in cold phosphate buffer, $\mathrm{pH} 7.0$ with ethylenediaminetetraacetic acid (EDTA), for TBARS measurement and cold $20 \mathrm{mM}$ N-(2-hydroxyethyl) piperazine-N'-2-ethanesulfonic acid (HEPES) buffer, $\mathrm{pH} 7.2$, containing $1 \mathrm{mM}$ ethyleneglycol-bis (2-aminoethoxy)-tetraacetic acid (EGTA), $210 \mathrm{mM}$ mannitol, and $70 \mathrm{mM}$ sucrose for SOD measurement (Mattiazzi et al. 2002). The supernatant was put in separate tubes and stored at $-70{ }^{\circ} \mathrm{C}$. Two milliliters of blood was separated into plasma and erythrocytes by centrifugation at 10,000 $\times \mathrm{g}$ for $10 \mathrm{~min}$ at $4{ }^{\circ} \mathrm{C}$. The erythrocyte samples were washed three times with cold physiological saline (PS) and then hemolyzed by adding a fourfold volume of icecold high-performance liquid chromatography (HPLC)grade water. Hemolyzed erythrocyte samples were centrifuged at $10,000 \times \mathrm{g}$ for $10 \mathrm{~min}$ at $4{ }^{\circ} \mathrm{C}$, and the supernatant was collected and stored at $-70{ }^{\circ} \mathrm{C}$ for less than three months prior to the measurement of enzymatic activity. It is known that antioxidant enzymatic activity is stable in hemolysates stored under such conditions (Andersen et al. 1997).

\section{Thiobarbituric acid reactive substances (TBARS)}

Lipid peroxidation levels were measured by the thiobarbituric acid (TBA) reaction using the method of Ohkawa et al. (1979). This method was used to measure spectrophotometrically the color produced by the reaction of TBA with malondialdehyde (MDA) at $532 \mathrm{~nm}$. For this purpose, TBARS levels were measured using a commercial assay as the NWLSS ${ }^{\mathrm{TM}}$ Malondialdehyde Assay (NWLSS, WA, USA) according to the manufacturer's instructions. Tissue supernatant $(50 \mu \mathrm{l})$ or erythrocyte supernatant $(50 \mu \mathrm{l})$ were added to test tubes containing $2 \mu \mathrm{l}$ of butylated hydroxytoluene (BHT) in methanol. Next, $50 \mu \mathrm{l}$ of acid reagent (1 M phosphoric acid) was added and finally $50 \mu$ of TBA solution was added. The tubes were mixed vigorously and incubated for $60 \mathrm{~min}$ at $60{ }^{\circ} \mathrm{C}$. The mixture was centrifuged at $10,000 \times \mathrm{g}$ for $3 \mathrm{~min}$. The supernatant was put into wells on a microplate in aliquots of $75 \mu \mathrm{l}$, and its absorbance was measured with a BIO RAD Benchmark Plus plate reader at $532 \mathrm{~nm}$ (BIO RAD Laboratories, Inc., CA, USA). TBARS levels were expressed as nmol/mg protein in various organs (brain, liver, pancreas and skeletal muscle), and as nmol/g hemoglobin in erythrocyte hemolysates.

\section{Superoxide dismutase (SOD)}

SOD activity in the tissue supernatants or the blood was measured as previously described (Sun et al. 1988). For this purpose, SOD activity was measured using a commercially supplied assay kit of Superoxide Dismutase Assay Kit (Cayman Chemical, MI, USA) according to the manufacturer's instructions. The SOD assay consisted of a combination of the following reagents: $0.3 \mathrm{mM}$ xanthine oxidase, $0.6 \mathrm{mM}$ diethylenetriamine-penta acetic acid (DETAPAC), $150 \mu \mathrm{M}$ nitroblue tetrazolium (NBT), $400 \mathrm{mM}$ sodium carbonate $\left(\mathrm{Na}_{2} \mathrm{CO}_{3}\right)$, and bovine serum albumin $(1 \mathrm{~g} / 1)$. The principle of the method is based on the inhibition of NBT reduction by superoxide radicals produced by the xanthine/xanthine oxidase system. The SOD stock solutions $(0-200 \mu \mathrm{l})$ for SOD standard activities (0-0.25 U/ml) contained $20 \mu \mathrm{l}$ of $\mathrm{Cu} / \mathrm{Zn}-\mathrm{SOD}$ from bovine erythrocyte dissolved in $1.98 \mathrm{ml}$ of $50 \mathrm{mM}$ Tris$\mathrm{HCl}, \mathrm{pH} 8.0$; before being used in the assay, this solution was diluted by adding $18 \mathrm{ml}$ of HPLC-grade water. For the assay, standard SOD solutions, tissue supernatant (10 $\mu \mathrm{l})$ or erythrocyte supernatant $(10 \mu \mathrm{l})$ were added to wells containing $200 \mu \mathrm{l}$ of NBT solution that was diluted by adding $19.95 \mathrm{ml}$ of $50 \mathrm{mM}$ Tris-HCl, $\mathrm{pH} 8.0$, containing $0.1 \mathrm{mM}$ DETAPAC solution and $0.1 \mathrm{mM}$ hypoxanthine. Finally, $20 \mu \mathrm{l}$ of xanthine oxidase was added to the wells at an interval of $20 \mathrm{~s}$. After incubation at $25{ }^{\circ} \mathrm{C}$ for $20 \mathrm{~min}$, the reaction was terminated by the addition of $1 \mathrm{ml}$ of $0.8 \mathrm{mM}$ cupric chloride. The formazan was measured spectrophoto-metrically by reading the absorbance at $560 \mathrm{~nm}$. One unit (U) of SOD is defined as the amount of protein that inhibits the rate of NBT reduction by $50 \%$. The calculated SOD activity was expressed as U/mg protein in various organs (brain, 

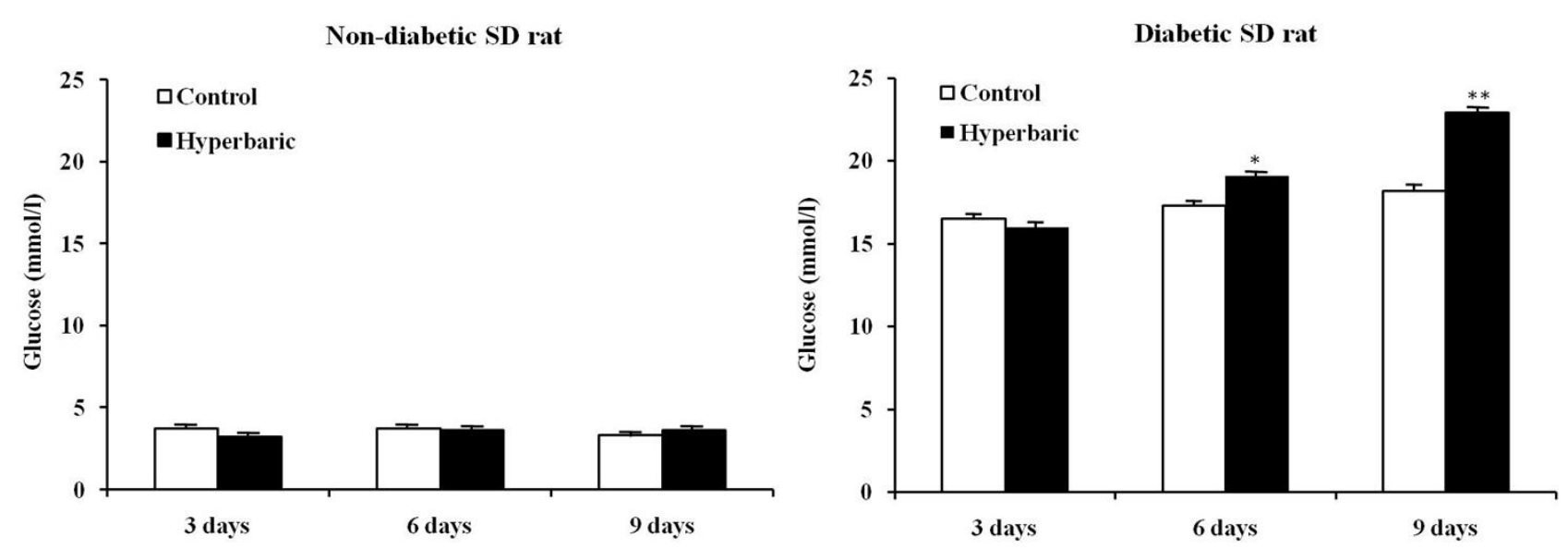

Fig. 1. Blood glucose levels in non-diabetic and diabetic Sprague-Dawley rats. Values are expressed as mean \pm S.D. $(n=6)$. $* p<0.01$, ** $p<0.001$ when compared with control value.

liver, pancreas and skeletal muscle), and as $\mathrm{U} / \mathrm{g}$ hemoglobin in erythrocyte hemolysates.

\section{Statistical analysis}

The collected and calculated data are expressed as mean \pm standard deviation (S.D.). Student's $t$-test was used to determine significant differences between the control and hyperbaric groups. For the analysis of TBARS levels and SOD activity data, analysis of variance (ANOVA) and a non-parametric test (KruskalWallis) were used. Differences were considered statistically significant if $p<0.05$.

\section{Results}

The body weight of the rats at beginning of the study was similar in all groups. At the end of the treatment (after 9 days), there was no difference in body weight between control and HBO rats. However, diabetic rats had a considerable weight loss, and the body weight of $\mathrm{DM}+\mathrm{HBO}$ rats $(299 \pm 8 \mathrm{~g})$ decreased significantly $(p<0.05)$, when compared with the rats in other three groups (control 354 $\pm 11 \mathrm{~g}$; HBO $353 \pm 5 \mathrm{~g}$; DM $320 \pm 8 \mathrm{~g}$ ).

The blood glucose levels of DM + HBO group were significantly higher at 6 and 9 days after diabetes induction $(p<0.05)$ as compared with DM group (Fig. 1). No significant differences were observed between control and HBO groups or experimental periods. Thus, HBO treatment resulted in a significant enhancement of blood glucose levels in diabetes with hyperglycemia.

TBARS levels and SOD activity in erythrocytes and all organs examined are presented in Figures 2 and 3. TBARS levels in HBO, DM, and DM + HBO groups were significantly increased ( $p<0.001-0.05)$, as compared with control group. In addition, TBARS levels in erythrocytes and all organs were higher in HBO group than in DM group $(p<0.01-0.05)$. Furthermore, HBO treatment was associated with a significant increase in TBARS levels $(p<0.001$; DM + HBO group vs. HBO and DM groups). The SOD activity in all samples examined in $\mathrm{HBO}, \mathrm{DM}$, and DM + HBO groups was significantly decreased $(p<0.001-0.05)$, as compared with control group. Moreover, SOD activity in erythrocytes and organs (pancreas, skeletal muscle, and brain) was lower in HBO group than in DM group $(p<0.001-0.05)$. Furthermore, HBO treatment was associated with a significant decrease in SOD activity $(p<0.001$; DM + HBO group vs. HBO and DM groups).

\section{Discussion}

The present study demonstrated for the first time that HBO significantly causes the enhancement of ROS production in STZ-induced diabetic rats, a recognized model of type 1 diabetic mellitus (T1DM). In addition to oxidative parameters, we have clearly demonstrated the changes in blood glucose levels. Hyperglycemia caused by diabetes is known to be a cause of oxidative stress that leads mainly to enhanced production of mitochondrial ROS (Brownlee 2001, Jay et al. 2006, Kowluru et al. 2007). Furthermore, oxidative stress induced by hyperglycemia leads to the activation of stress-sensitive signaling pathways, which worsen both insulin secretion and action, and promote the development of type 2 diabetic mellitus (T2DM) (Evans et al. 2002). Similarly, oxidative stress and damage to the tissues and the blood in STZ-induced diabetic rats enhance glucose autoxidation, and may be a factor contributing to 

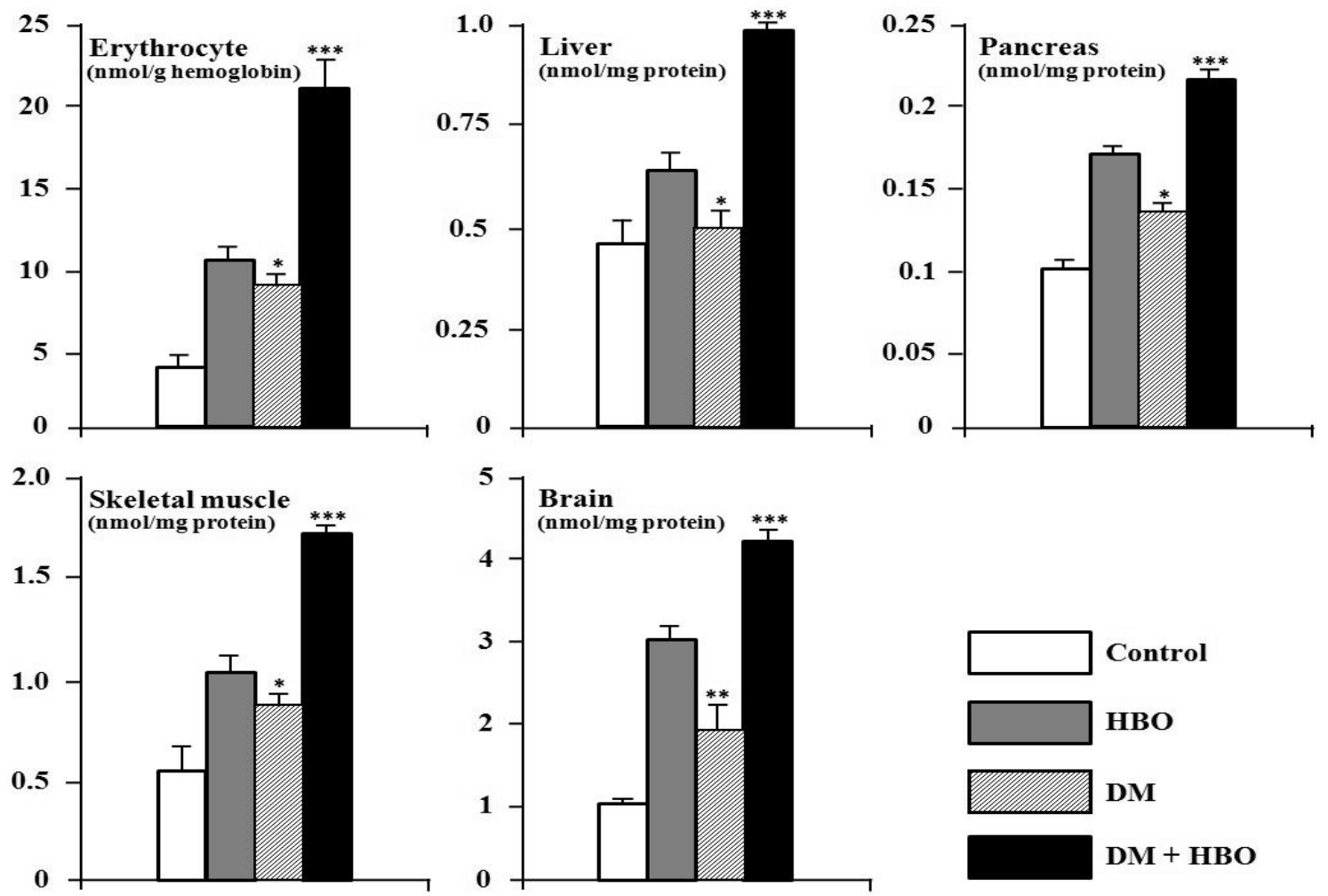

Fig. 2. Lipid peroxidation content (TBARS) in the erythrocytes and organs (liver, pancreas, skeletal muscle, brain) of all groups. Control (non-diabetic rats without HBO), HBO (non-diabetic rats with $\mathrm{HBO}$ ), DM (diabetic rats without HBO), and DM + HBO (diabetic rats with $\mathrm{HBO}$ ) groups. TBARS values are indicated as $\mathrm{nmol} / \mathrm{g}$ hemoglobin in erythrocytes and as $\mathrm{nmol} / \mathrm{mg}$ protein in various organs. Values are expressed as mean \pm S.D. $(n=6) . * p<0.05, * * p<0.01, * * * p<0.001$ when compared with HBO and DM groups.
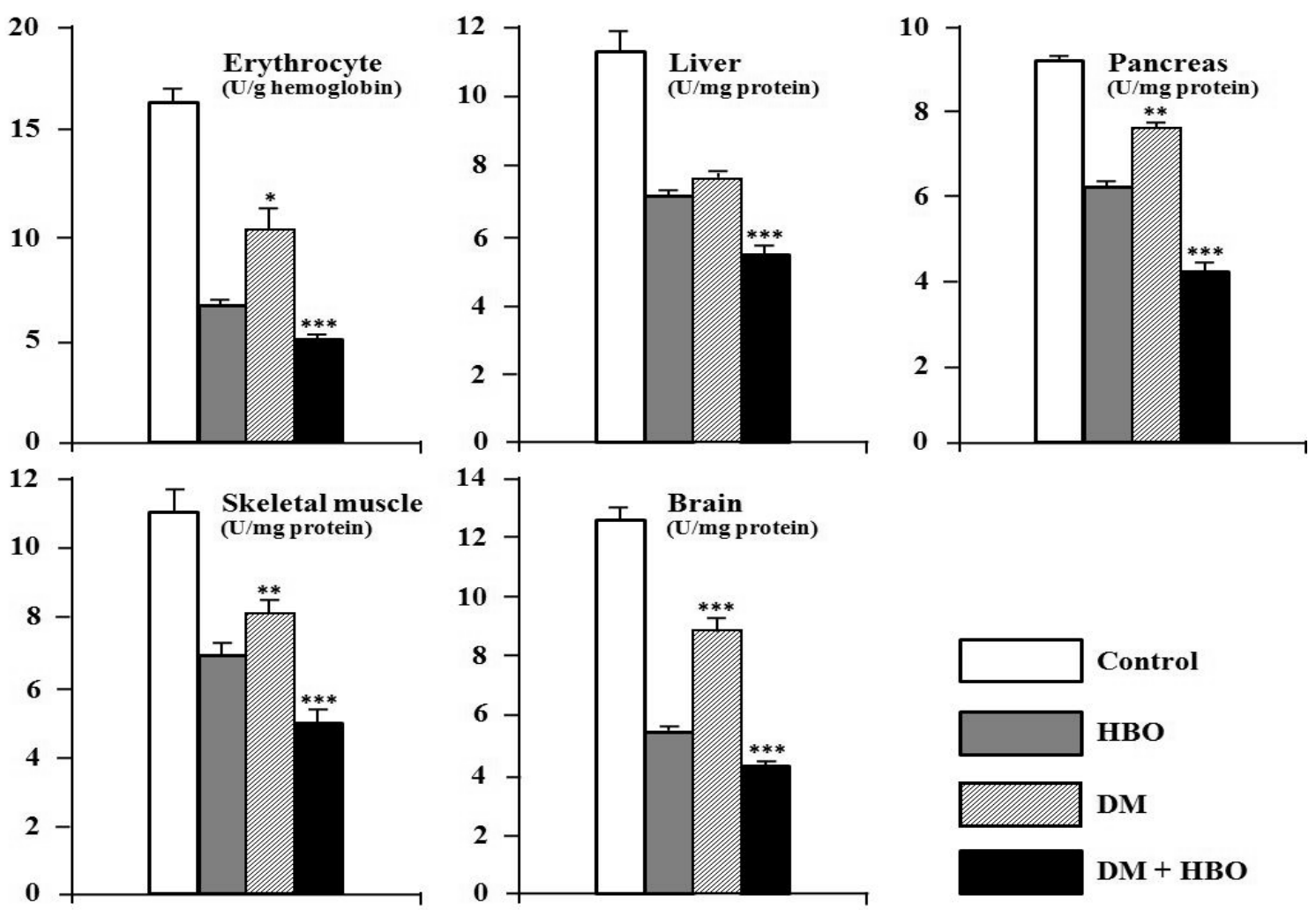

Fig. 3. Antioxidant enzyme (SOD) activity in the erythrocytes and organs (liver, pancreas, skeletal muscle, brain) of all groups. For other legend see Fig. 2. 
complications associated with diabetes (Kakkar et al. 1995). A recent study has reported that TBARS levels are elevated and activities of antioxidant enzymes (SOD, glutathione peroxidase, and catalase) are significantly reduced in STZ-induced diabetic rats (Jin et al. 2008). Therefore, we further examined the oxidative effects of HBO in STZ-induced diabetic rats, and found that the TBARS levels and SOD activity of diabetic rats were significantly affected by HBO treatment.

HBO exposure leads to an increase in the amount of oxygen dissolved in the blood, resulting in the improvement of a variety of clinical conditions such as hypoxia, acute carbon monoxide intoxication, air embolism and diabetic lower limb wounds (Feldmeier 2003, Lipsky et al. 2004). The most commonly used doses of HBO for standard therapeutic purposes are 1.8-2.8 ATA for 60-90 min (Benedetti et al. 2004). Although the oxidative effects of HBO have been investigated in animals and humans (Chavko et al. 1996, Eken et al. 2005, Oter et al. 2005, Korkmaz et al. 2008), the HBO conditions applied in previous studies seemed to be higher than usual therapeutic levels. For example, one study in rats revealed that, after HBO exposure at 3 ATA, oxidative stress markers, including TBARS levels and SOD, glutathione peroxidase, and nitrate/nitrite (NOx) activity, were found to be elevated in the brain (Korkmaz et al. 2008). In the present study, we used an HBO exposure protocol based on clinically used oxygen pressure and exposure duration, and we investigated blood glucose levels, in addition to TBARS levels and SOD activity in erythrocytes, liver, pancreas, skeletal muscle, and brain of rats with STZ-induced diabetes. Our results showed that blood glucose levels were not improved in HBO-treated diabetic rats, suggesting that clinically used HBO administration might enhance the functional disorder of pancreatic cells. In addition, the levels of blood glucose in nondiabetic rats with $\mathrm{HBO}$ treatment remained stable also in our previous study (Matsunami et al. 2008). On the other hand, we showed that the levels of TBARS were significantly higher in non-diabetic rats with $\mathrm{HBO}$ treatment than in diabetic rats without HBO treatment. As TBARS levels are closely associated with lipid peroxidation (Ohkawa et al. 1976, Chavko et al. 1996, Opara 2002, Eken et al. 2005), these results suggest that lipid peroxidation is greater under the conditions of continuous HBO exposure than under DM condition. Previously, we have shown for the first time in STZdiabetic rats that the increase in blood glucose levels started after the initiation of HBO treatment administered at a clinically relevant pressure level and duration (Matsunami et al. 2008). Furthermore, in the present study, we have shown that diabetic rats receiving $\mathrm{HBO}$ treatment had significantly increased TBARS levels and significantly decreased SOD activity as compared with the diabetic control group (without HBO treatment).

Interestingly, it has been shown that blood glucose levels are decreased by HBO treatment in GotoKakizaki (GK) rats, an animal model of spontaneous type 2 DM, suggesting that HBO could interfere with the activity of the natural anti-oxidative defense system and thus promote de novo generation of free radicals (Ihara et al. 1999, Maritim et al. 2003, Yasuda et al. 2007). Our results suggest that the mode of action of HBO on the glucose control system might be different in STZ- and GK-induced diabetic rats. The possible side-effects of HBO seen in this study - namely, the elevation of glucose levels in the peripheral blood might occur as a result of the enhancement of STZ cytotoxicity by $\mathrm{HBO}$ administration as shown in our previous study (Matsunami et al. 2008). The probable cause of the enhancement of glucose toxicity or autoxidation might be oxidative stress as described previously (Hunt et al. 1990, Wolff et al. 1991, Ihara et al. 1999, Maritim et al. 2003). It is widely accepted that HBO administration increases superoxide and SOD activity, and there is no doubt that HBO causes lipid peroxidation (Oury et al. 2002). However, it has been demonstrated that the enhancement of SOD activity by HBO administration is due to intermittent or single HBO exposure, and SOD activity decreases with continuous HBO exposure (Harabin et al. 1990). Our study showed that HBO treatment significantly increased TBARS levels and decreased SOD activity, clearly demonstrating that HBO causes oxidative stress in type $1 \mathrm{DM}$. Thus, the synergistic elevation of blood glucose levels between STZ-induced diabetes and HBO treatment might lead to glucose autoxidation, which would increase the induction of ROS. Our experimental system, which uses STZ-induced diabetes with HBO treatment, could be applied for evaluating the manifold toxicities of insulin resistance and metabolic syndrome in DM, by monitoring the unusual increases in blood glucose levels and oxidative stress.

\section{Conflict of Interest}

There is no conflict of interest. 


\section{Acknowledgements}

This study was partially supported by the Academic Frontier Project "Surveillance and Control for Zoonoses" from Ministry of Education, Culture, Sports, Science and Technology, Japan.

\section{References}

ANDERSEN HR, NIELSEN JB, NIELSEN F, GRANDJEAN P: Antioxidative enzyme activities in human erythrocytes. Clin Chem 43: 562-568, 1997.

BENEDETTI S, LAMORGESE A, PIERSANTELLI M, PAGLIARANI S, BENVENUTI F, CANESTRARI F: Oxidative stress and antioxidant status in patients undergoing prolonged exposure to hyperbaric oxygen. Clin Biochem 37: 312-317, 2004.

BROWNLEE M: Biochemistry and molecular cell biology of diabetic complications. Nature 414: 813-820, 2001.

CHAVKO M, HARABIN AL: Regional lipid peroxidation and protein oxidation in rat brain after hyperbaric oxygen exposure. Free Radic Biol Med 20: 973-978, 1996.

DAVI G, FALCO A, PATRONO C: Lipid peroxidation in diabetes mellitus. Antioxid Redox Signal 7: 256-268, 2005.

EKEN A, AYDIN A, SAYAL A, USTUNDAG A, DUYDU Y, DUNDAR K: The effects of hyperbaric oxygen treatment on oxidative stress and SCE frequencies in humans. Clin Biochem 38: 1133-1137, 2005.

EVANS JL, GOLDFINE ID, MADDUX BA, GRODSKY GM: Oxidative stress and stress-activated signaling pathways: a unifying hypothesis of type 2 diabetes. Endocr Rev 23: 599-622, 2002.

FELDMEIER JJ: Hyperbaric Oxygen: Indications and Results; the Hyperbaric Oxygen Therapy Committee Report. Undersea and Hyperbaric Medical Society, North Carolina, USA, 2003.

HARABIN AL, BRAISTED JC, FLYNN ET: Response of antioxidant enzymes to intermittent and continuous hyperbaric oxygen. $J$ Appl Physiol 69: 328-335, 1990.

HUNT JV, SMITH CC, WOLFF SP: Autoxidative glycosylation and possible involvement of peroxides and free radicals in LDL modification by glucose. Diabetes 39: 1420-1424, 1990.

IHARA Y, TOYOKUNI S, UCHIDA K, ODAKA H, TANAKA T, IKEDA H, HIAI H, SEINO Y, YAMADA Y: Hyperglycemia causes oxidative stress in pancreatic beta-cells of GK rats, a model of type 2 diabetes. Diabetes 48: 927-932, 1999.

JAY D, HITOMI H, GRIENDLING KK: Oxidative stress and diabetic cardiovascular complications. Free Radic Biol Med 15: 183-192, 2006.

JIN L, XUE HY, JIN LJ, LI SY, XU YP: Antioxidant and pancreas-protective effect of aucubin on rats with streptozotocin-induced diabetes. Eur J Pharmacol 582: 162-167, 2008.

KAKKAR R, KALRA J, MANTHA SV, PRASAD K: Lipid peroxidation and activity of antioxidant enzymes in diabetic rats. Mol Cell Biochem 151: 113-119, 1995.

KORKMAZ A, OTER S, SADIR S, TOPAL T, UYSAL B, OZLER M, AY H, AKIN A: Exposure time related oxidative action of hyperbaric oxygen in rat brain. Neurochem Res 33: 160-166, 2008.

KOWLURU RA, CHAN PS: Oxidative stress and diabetic retinopathy. Exp Diabetes Res 2007: 43603, 2007.

LIKE AA, ROSSINI AA: Streptozotocin-induced pancreatic insulitis: new model of diabetes mellitus. Science 193: 415-417, 1976.

LIPSKY BA, BERENDT AR, DEERY HG., EMBIL JM, JOSEPH WS, KARCHMER AW, LEFROCK JL, LEW DP, MADER JT, NORDEN C, TAN JS: Diagnosis and treatment of diabetic foot infections. Clin Infect Dis 39: 885-910, 2004.

MARITIM AC, SANDERS RA, WATKINS JB $3^{\text {rd }}$ : Effects of alpha-lipoic acid on biomarkers of oxidative stress in streptozotocin-induced diabetic rats. J Nutr Biochem 14: 288-294, 2003.

MATKOVICS B, KOTORMAN M, VARGA IS, HAI DQ, VARGA C: Oxidative stress in experimental diabetes induced by streptozotocin. Acta Physiol Hung 85: 29-38, 1997.

MATSUNAMI T, SATO Y, MORISHIMA T, MANO Y, YUKAWA M: Enhancement of glucose toxicity by hyperbaric oxygen exposure in diabetic rats. Tohoku J Exp Med 216: 127-132, 2008. 
MATTIAZZI M, D'AURELIO M, GAJEWSKI CD, MARTUSHOVA K, KIAEI M, BEAL MF, MANFREDI G: Mutated human SOD1 causes dysfunction of oxidative phosphorylation in mitochondria of transgenic mice. J Biol Chem 277: 29626-29633, 2002.

OHKAWA H, OHISHI N, YAGI K: Assay for lipid peroxides in animal tissues by thiobarbituric acid reaction. Anal Biochem 95: 351-358, 1979.

OPARA EC: Oxidative stress, micronutrients, diabetes mellitus and its complications. J R Soc Promot Health 122: 2834, 2002.

OTER S, KORKMAZ A, TOPAL T, OZCAN O, SADIR S, OZLER M, OGUR R, BILGIC H: Correlation between hyperbaric oxygen exposure pressures and oxidative parameters in rat lung, brain, and erythrocytes. Clin Biochem 38: 706-711, 2005.

OURY TD, SCHAEFER LM, FATTMAN CL, CHOI A, WECK KE, WATKINS SC: Depletion of pulmonary EC-SOD after exposure to hyperoxia. Am J Physiol 283: L777-L784, 2002.

PRASAD K, LEE P, MANTHA SV, KALRA J, PRASAD M, GUPTA JB: Detection of ischemia-reperfusion cardiac injury by cardiac muscle chemiluminescence. Mol Cell Biochem 115: 49-58, 1992.

SIES H: Oxidative stress: oxidants and antioxidants. Exp Physiol 82: 291-295, 1997.

SPEIT G, DENNOG C, RADERMACHER P, ROTHFUSS A: Genotoxicity of hyperbaric oxygen. Mutat Res 512: 111$119,2002$.

SUN Y, OBERLEY LW, LI Y: A simple method for clinical assay of superoxide dismutase. Clin Chem 34: 497-500, 1988.

TORBATI D, CHURCH DF, KELLER JM, PRYOR WA: Free radical generation in the brain precedes hyperbaric oxygen-induced convulsions. Free Radic Biol Med 13: 101-106, 1992.

WOLFF SP, JIANG ZY, HUNT JV: Protein glycation and oxidative stress in diabetes mellitus and ageing. Free Radic Biol Med 10: 339-352, 1991.

YASUDA K, ADACHI T, GU N, MATSUMOTO A, MATSUNAGA T, TSUJIMOTO G, TSUDA K, ISHIHARA A: Effects of hyperbaric exposure with high oxygen concentration on glucose and insulin levels and skeletal muscle-fiber properties in diabetic rats. Muscle Nerve 35: 337-343, 2007. 